mental pathways in higher organisms. In a general sense this is true because, logically, the $\lambda$ system appropriately combines positive and negative feedback in a simple way to implement a switch; but this is not necessarily the only way it can be done. Years ago Novick performed a most illuminating experiment. Normally the galactosidase of Escherichia coli is repressed, but it can be released from repression (induced) in the presence of lactose or an analogue thereof. Novick briefly exposed E.coli cultures to a high concentration of an inducer which was then diluted a thousandfold to provide a maintenance level. In a fraction of the cells, enough of the inducer got in to derepress the genes; the rest remained uninduced. The resulting mixed population maintained itself indefinitely as long as the low level of inducer was present, because induction entails the production of a permease that increases the uptake of the inducer so that even at low levels enough can enter the cells to maintain the induced state. Thus it could be said that $E$.coli had "differentiated" into two cell types with heritable states. This result depends on the properties of the permease: only cells with permease can take up inducer at the low maintenance level and only such cells can have permease induced; transient induction at high levels simply initiates the process in part of the population. Here the logical elements of positive and negative feedback are implemented in another way and it is arguably a better paradigm for some developmental processes than the $\lambda$ switch.

The analogy between the $\lambda$ switch and developmental processes should not be carried too far. In discussing the difference between "commitment" and "differentiation" of cells, Ptashne writes

By analogy, a $\lambda$-lysogen is indistinguishable from an uninfected bacterium by casual inspection, but the former and not the latter is 'committed' to lyse and release phage when it encounters an inducing signal in the environment.

However, he quickly realizes that this is not a good analogy because the difference between the bacteria is a genetic one and he continues

The lysogen, of course, has genes that are lacking in the non-lysogen, but it is not difficult to imagine analogous forms of commitment involving only differential gene expression. To take a simple example, the regulatory proteins of a cell might turn on a gene encoding a hormone receptor.

Do we hear a faint echo of the permease paradigm?

But this is quite a minor criticism of a clear exposition of a series of triumphant experiments and insights that have brought us close to the molecular heart of the matter of genetic regulation.

Sydney Brenner is Head of the Medical Research Council Molecular Genetics Unit, Hills Road, Cambridge CB2 $2 Q H$, UK. \section{Eastern originality}

\section{Christopher Cullen}

China: Land of Discovery and Invention. By Robert K. G. Temple. Patrick Stephens, Wellingborough, UK: 1986. Pp.248. £12.95.*

READERS of this journal will need no more than a brief reminder of the importance of the work of Joseph Needham. With the help of a large group of collaborators, over the past 40 years he has been engaged in a great project of research and publication on the history of science, technology and medicine in pre-modern China. The results are appearing in the pages of $\mathrm{Sci}$ ence and Civilisation in China, the seven volumes of which are being published by Cambridge University Press as some 30 separate tomes (about half of them have appeared to date). This work is widely regarded as the most influential British contribution to historical scholarship in the present century, and it has certainly completely changed the perspective of many well-informed Westerners on the origin of important aspects of modern science.

As the weight of his research has accumulated, Needham has had to move far from his original aim of writing a short book for the general reader. Robert Temple's book, which is compiled almost entirely on the basis of material already published or awaiting publication in Needham's volumes, is intended to meet this need. Temple has divided his account into 11 broad subject areas, such as. "Agriculture, Medicine and Health", "Magnetism" and "Warfare". Under these he has grouped a hundred short, illustrated essays on particular topics. Temple is clearly no mere hack compiler of coffeetable books: his writing is clear and vigorous, and he succeeds in communicating his obvious enthusiasm for the subject. It is hard to imagine anyone with a general interest in the history of science failing to find a great deal in this book to intrigue and delight.

There are some flaws. Temple makes no systematic attempt at writing history; the book is a series of vignettes on "the wonders of Chinese science", and as such does not convey any sense of the social and philosophical background from which Chinese science, technology and medicine arose and against which they functioned. The choice of topics and the balance between them sometimes seems odd: the section on engineering devotes more space to the novelties known as "spouting bowls" than to cast iron. Some of the statements are out of date or just plain wrong, and the one-page list of "further reading" is so incomplete that it does not even mention Colin Ronan's readable and reasonably priced abridgement of Needham's work, also published by Cambridge University Press. On the whole, however, Temple deserves the gratitude of his readers for having provided a ready means of access to a fascinating subject. $\square$

Christopher Cullen, 86 Mount View Road, London N4 4JX, UK, is a former Research Fellow of Clare Hall, Cambridge, and has published mainly in the field of ancient Chinese astronomy and mathematics.

*To be published in the United States in January by Simon \& Schuster, under the title The Genius of China: 3000 Years of Science, Discovery, and Invention. Price will be $\$ 19.95$.

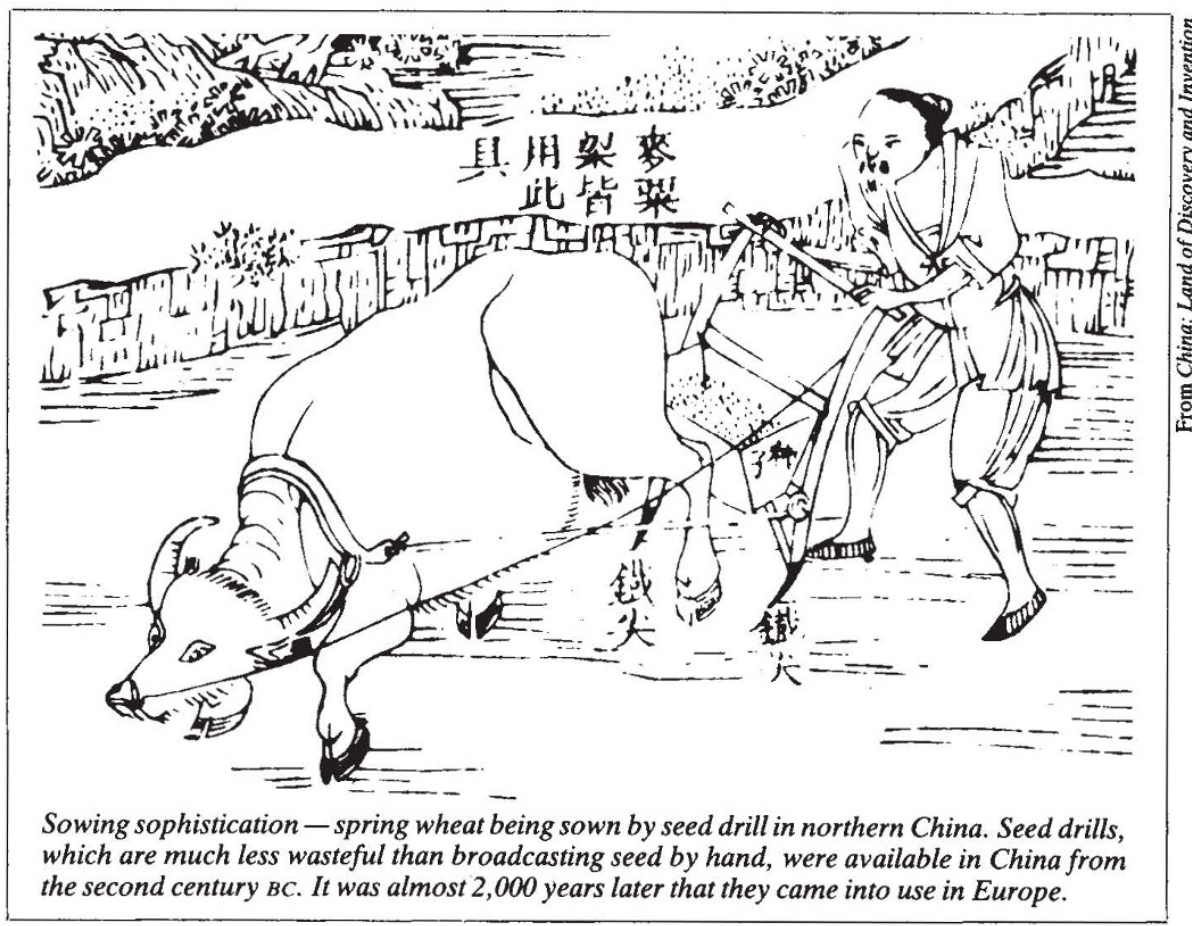

